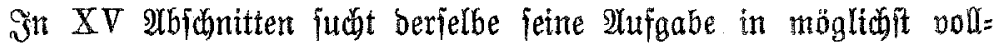

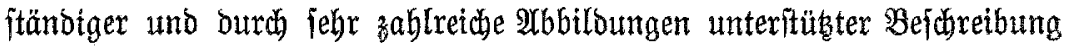
ber außeroroentltă mannigfachen Geräte und Şilfegmittel, berent fith bie

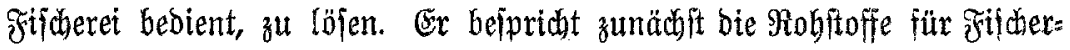

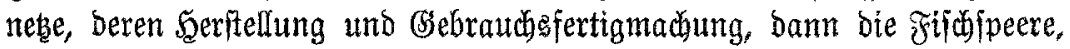

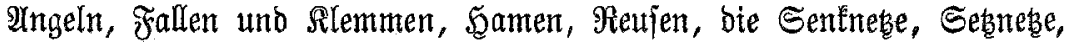
Wurfnebe, Bugnete und hie bei lethteren vielfach benübten Fif Gerwinden.

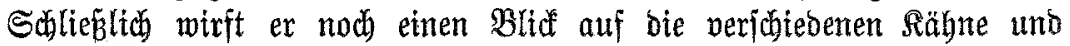
Jahrzeuge, beren fich bie \$intnenfijcher bebienen, jonte auf bie zatr $2 \mathfrak{U f}=$

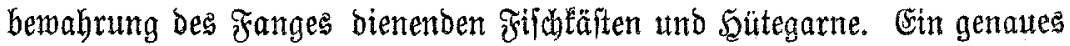

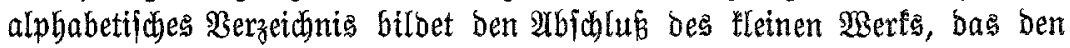

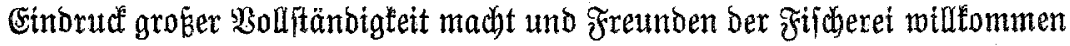
jein oürfte.

r.

\title{
IV. Ilutizen.
}

Wirft der Efeu făädigend auf Bäune und Baumerte?

Die Frage, ob ber Sfen fdäbigento auf $\mathfrak{B a ̈ u m e}$ wirle, wirb wohl alfgentein

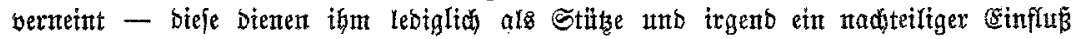
auf Badistum unb Entmidfluttg bes Banmes befteht nidut.

(atwas zmeifelfafter erjdien biefe Frage bezüglitu ber Banmerfe, bie wir fo oft bidt mit Efen ïberzogen feben. General= Ronferbator Dr. \$ager in Mündjen bat biefe

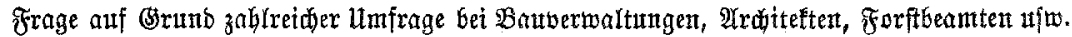
itt einem Bortrag (Danzig 1910) behanbelt unb mitgetetlt, baß̉ bie überwiegentbe Mebr

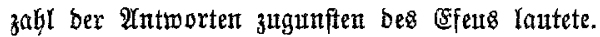

Der. Efen madt weber bie Bänoe fendt, now fprengt or fie burd Cinbringen

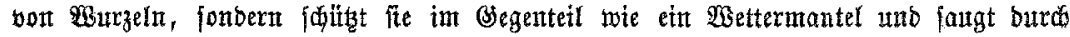

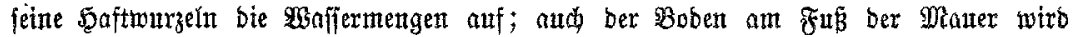

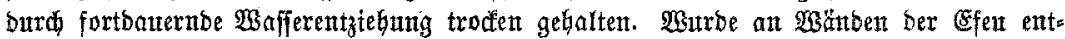
fernt, fo zeigte fich bie Mauer glatt unb unverletst, auth Futboment unb Mouerung

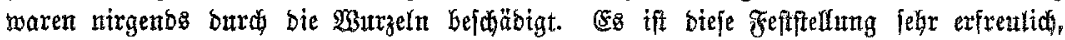

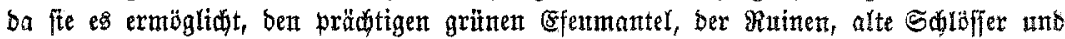

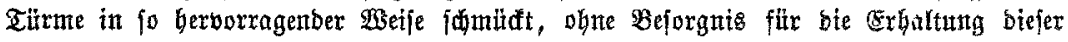
Bautwerte za belafien. 